\title{
Combining multi-criteria and space syntax analysis to assess a pedestrian network: the case of Oporto
}

\author{
Mona Jabbari (D), Fernando Fonseca (D) and Rui Ramos \\ CTAC - Centre for Territory, Environment and Construction, School of Engineering, University of Minho, Braga, \\ Portugal
}

\begin{abstract}
This paper describes a GIS-based integrated approach to assess a pedestrian network by combining multi-criteria and space syntax. The analysis combines pedestrian attributes with street connectivity and both factors were evaluated by a group of experts. The approach was adopted in the city of Oporto. Results show that the city centre offers various conditions; however, overall they are poor for pedestrians. Moreover, the streets which scored best are not integrated into the network. The described approach can potentially be replicated in other cities in terms of improving the walkability and promoting sustainable urban mobility.
\end{abstract}

\section{Introduction}

Walkability is seen as one of the most important concepts for sustainable urban development and sustainable mobility (Forsyth and Southworth 2008). The personal, social, economic and environmental benefits of walking, both as a leisure activity and a mode of transport, are well-documented: walking reduces traffic congestion and pollution; it is beneficial to individuals' health and well-being; it has health-economic benefits; it affects real estate prices; and improves the sociability and vitality of urban spaces (Bahrainy and Khosravi 2013; Kim, Park, and Lee 2014; Lee and Talen 2014; Longo et al. 2015).

For these reasons, encouraging people to walk has been included in various policies and has become a main issue for urban planners during recent decades. For example, the White Paper on Transport (EC 2011) and the Sustainable Urban Mobility Plans launched by the European Union are focused on encouraging walkability in cities.

Actions to promote walkability have mainly concentrated on making this form of travel easy and attractive by: improving the general quality of built environments (Kim, Park, and Lee 2014); providing walking facilities (Koh and Wong 2013; Li, Gao, and Yin 2013; Longo et al. 2015) and green areas (Panagopoulos, Duque, and Dan 2016); and by enhancing the physical and functional linkage between urban spaces (Kasemsuppakorn and Karimi 2013; Babiano 2016). Understanding the factors that influence walkability and pedestrians' perceptions enables planners to build more walkable and liveable cities. As some authors show, 
conditions provided to pedestrians influence their decision to walk, as well as aspects such as the walking distance, walking time and satisfaction of walking (Kim, Park, and Lee 2014).

This paper describes a GIS-based integrated approach to assess a pedestrian network in the city centre of Oporto by using multi-criteria and space syntax analysis. The multi-criteria analysis (MCA) was performed by using four criteria and nine sub-criteria that mostly influence walkability. The criteria selection was supported by an extensive literature review and by experts' evaluations. Space syntax was used to evaluate street connectivity. Results of multi-criteria and street connectivity were normalized using fuzzy logic, namely by developing sigmoid and linear functions to compare them. The outcome led to ranking streets according to their walkable conditions and a map showing the network and level of connectivity between them. By combining nine sub-criteria with street connectivity, this paper makes an innovative contribution to the literature on walkability and provides urban planners and developers with a useful tool. As the approach identifies the less walkable streets and the problems in their linkages, results can be used by urban planners to improve walkability and, consequently, liveability, making cities more sustainable.

This paper is organized as follows. The next section presents the theoretical framework, focusing on key aspects linked to pedestrians. The following section explains the methodology adopted in the study. There is then a brief description of the city of Oporto. Next, the results are presented and discussed. The last section summarizes the final remarks.

\section{Literature review}

Opting to walk and which route to take are different but related decisions because they are influenced by some of the same factors. Individuals' decisions about where and whether to walk are highly complex and typically entail considering multiple factors, including distance and time to walk, perceived ease, comfort, safety, security, convenience, proximity and attractiveness of the route, and are influenced by age, gender, ethnicity, income, household size, car ownership, built environment, route characteristics, among others (Agrawal, Schlossberg, and Irvin 2008; Koh and Wong 2013; Nasir et al. 2014; Ferrer, Ruiz, and Mars 2015; Babiano 2016).

The literature on factors affecting walking has significantly increased over the last two decades. The built (or physical) environment is one of the most analyzed topics (Cervero et al. 2009; Walford et al. 2011; Nasir et al. 2014; Ferrer, Ruiz, and Mars 2015; Lamíquiz and Domínguez 2015). It corresponds to the physical context in which people spend their time (home, neighbourhood, school) and includes factors related to urban design, land use, walking facilities, traffic safety, aesthetics, access to facilities and slopes (Ferrer, Ruiz, and Mars 2015). A physical environment influences perceptions such as safety, security and comfort, which consequently determine satisfaction and the decision to walk (Bahrainy and Khosravi 2013; Nasir et al. 2014; Peiravian, Derrible, and ljaz 2014; Gilderbloom, Riggs, and Meares 2015).

Land use is an important factor influencing pedestrians' satisfaction and distribution in urban spaces (Bahrainy and Khosravi 2013; Lamíquiz and Domínguez 2015; Lerman and Omer 2016). Various studies show that mixed land uses and commercial areas increase pedestrian movements (Lamíquiz and Domínguez 2015; Lerman and Omer 2016). There are correlations between residential areas, population density and pedestrian movements 
(Christiansen et al. 2014; Peiravian, Derrible, and ljaz 2014; Lerman and Omer 2016), as well as between land use and distance. In fact, areas with mixed land use, allowing for multiple activities to be located close to each other, reduce the distance to be travelled (Maleki, Zain, and Ismail 2012; Azmi and Ahmad 2015).

Accessibility is another factor which has been extensively analyzed. Accessibility can be described as people's ability to reach a certain place making an acceptable effort (Geurs and van Wee 2004). The concept has particular connections with land use regarding the quality and spatial distribution of opportunities provided at each destination. It also has connections with modes of transport considering the disutility for an individual to cover the distance between an origin and a destination (Geurs and van Wee 2004). Walking to access other modes of transport, mainly public transport, is very common and encouraged in many countries (Cubukcu et al. 2015). Sung et al. (2015) found that shorter distances to public transportation increased street-level walking. Besides public transport, access to facilities, such as shops and stores (Koh and Wong 2013), amenities, such as schools (Christiansen et al. 2014), green areas (Panagopoulos, Duque, and Dan 2016), mixed-use areas (Cubukcu et al. 2015), among others can also be considered. Advanced transport technological solutions, such as real-time passenger information systems, can also improve accessibility (Velaga et al. 2012).

Urban design comprises various perceptual qualities that may affect the walking environment (Bahrainy and Khosravi 2013; Wey and Chiu 2013; Kim, Park, and Lee 2014; Garcia and Lara 2015). Although difficult to define, Ewing and Handy (2009) proposed the following five qualities: imageability, enclosure, human scale, transparency and complexity. These criteria have been used to create urban design quality indexes to explore aspects of the physical environment considering facets directly relevant to people's feelings towards aesthetics and structure in urban areas (Walford et al. 2011). Aesthetic quality has also been linked to walking as a means of transportation (Adkins et al. 2012; Ferrer, Ruiz, and Mars 2015). Aesthetics includes sensorial effects and stimulus that pedestrians can experience creating pleasant walking experiences (Ferrer, Ruiz, and Mars 2015). Thus, the physical environment, urban design and aesthetics are interdependent factors which result in adopting appropriate planning policies.

Slopes are also an important factor, as small positive increments in slopes decrease travel speeds while increasing energy use and travel (Lundberg and Weber 2014). If a route has steps or upward slopes, pedestrians may avoid that way. However, a slight downward slope will help walking as less effort is needed (Koh and Wong 2013).

The natural environment is also an important factor, which influences walking (Lundberg and Weber 2014; Panagopoulos, Duque, and Dan 2016). Comfortable conditions, including temperature, green space, sunlight, shade and wind are important for walking (Koh and Wong 2013). Green spaces not only direct pedestrian flow in wide streets, improving pedestrians' perception of privacy and safety regarding car traffic, but also benefit the urban environment.

Street connectivity is seen as having an important impact on walking and on defining how streets are networked (Bahrainy and Khosravi 2013; Azmi and Ahmad 2015). Street connectivity can be understood as the directness and availability of alternative routes and can be defined as the number of intersecting streets per land-area unit (Azmi and Ahmad 2015; Garcia and Lara 2015). High street connectivity is typically found in areas with denser 
street networks. A higher number of road intersections provide more potential routes for walking, greater accessibility and shorter distances to destinations (Azmi and Ahmad 2015). Therefore, street connectivity has been considered in many walking indexes (Millward, Spinney, and Scott 2013; Kim, Park, and Lee 2014; Lee and Talen 2014; Peiravian, Derrible, and ljaz 2014; Gilderbloom, Riggs, and Meares 2015; Lerman and Omer 2016). Nonetheless, some research also shows that high street connectivity can lead to more street crossings, which incur safety risks for pedestrians and longer waiting times because of signalling (Ferrer, Ruiz, and Mars 2015). Thus, conveniently designed pedestrian crossings should be provided to encourage walking and to keep obstacles to a minimum.

This paper describes a GIS-based integrated approach to assess a pedestrian network by combining multi-criteria and space syntax. This tool is often used in spatial planning to help decision makers (Ramos and Fonseca 2016), including approaches to improve walkability and pedestrian accessibility (Blečić et al. 2015) and to create walking indexes (Millward, Spinney, and Scott 2013; Christiansen et al. 2014).

\section{Case study: the city of Oporto}

Oporto is the second largest city in Portugal. The city is located in the northwest of the country, and according to the last census (SP 2012) it has a population of 237,559 inhabitants. It is also the second biggest Portuguese metropolitan area with approximately 1.7 million inhabitants. The urban morphology of Oporto is significantly shaped by the Douro River and by the topography. The city started as a small medieval settlement on a hill and developed along the Douro River. The historic centre of Oporto developed under organic forms and narrow streets shaped by the rough terrain between the river and the city centre. In 1996, based on the outstanding universal value of the urban fabric and its many historic buildings bearing remarkable testimony to the development over the past thousand years, the historic centre of Oporto was classified by UNESCO as a World Heritage Site. The classified site is basically defined by the medieval walls having an area of approximately 90 hectares.

The pedestrian network described in this paper consists of the historic centre of Oporto and the neighbouring urban areas (Figure 1). The selected area has 262 hectares and corresponds to $7 \%$ of the city surface, integrating spaces with different urban functions, land use and densities that are linked by streets with different characteristics in terms of slopes, width, visual dimension, landscaping, etc. These different features provide a considerable variety of conditions for pedestrians, creating a varied and multifunctional space.

\section{Data and methods}

The methodological procedures adopted in the study will be described as follows: (1) general purpose and method; (2) criteria selection; (3) description of the data collection, weights assignment and aggregation method; and (4) assessment of the pedestrian network.

\section{General purpose and method}

The main steps of the study are shown in Figure 2. The first one was to define a general tool to analyze the walkability and connectivity of the pedestrian network. The MCA was adopted 


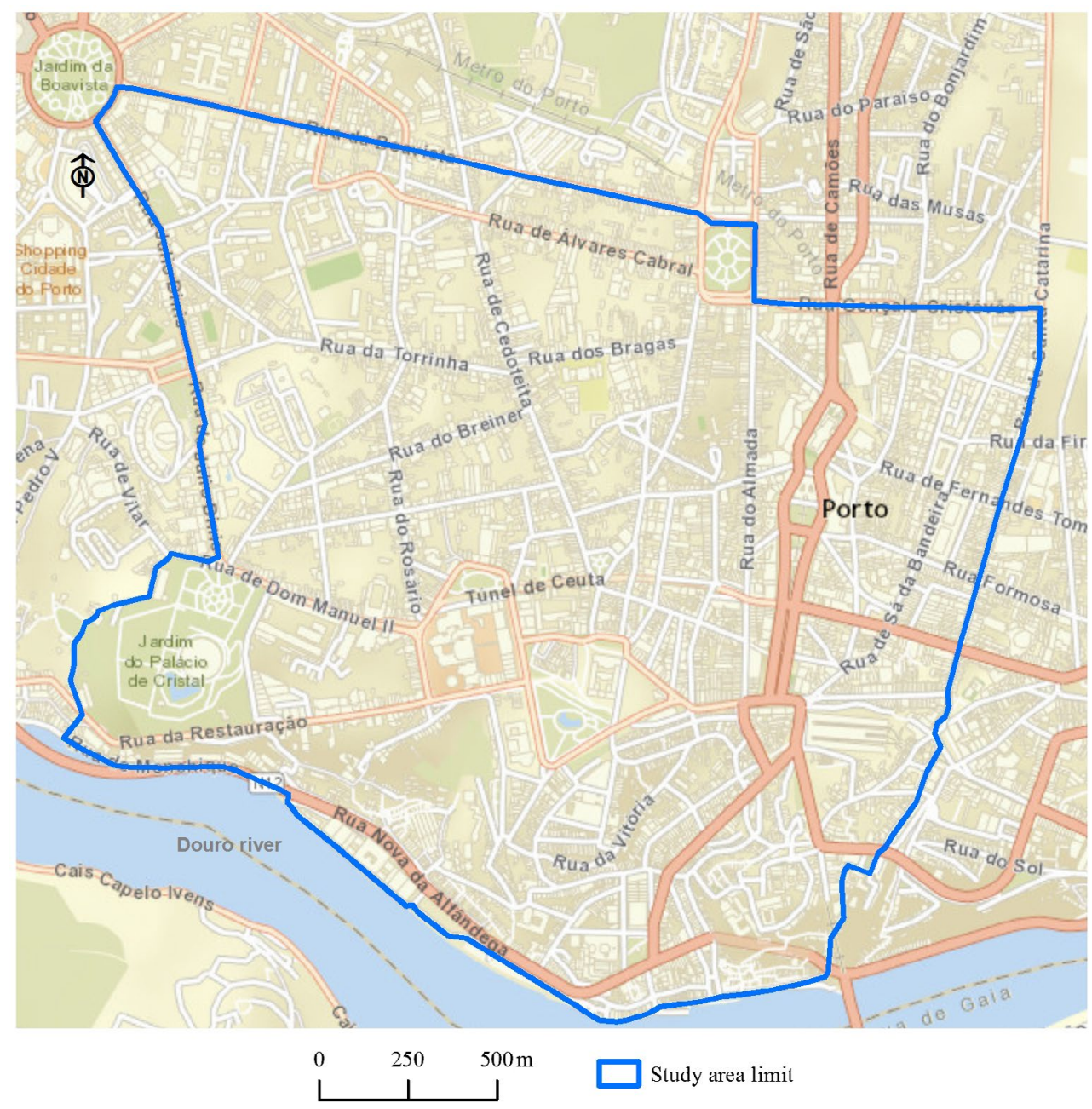

Figure 1. The study area in the city centre of Oporto.

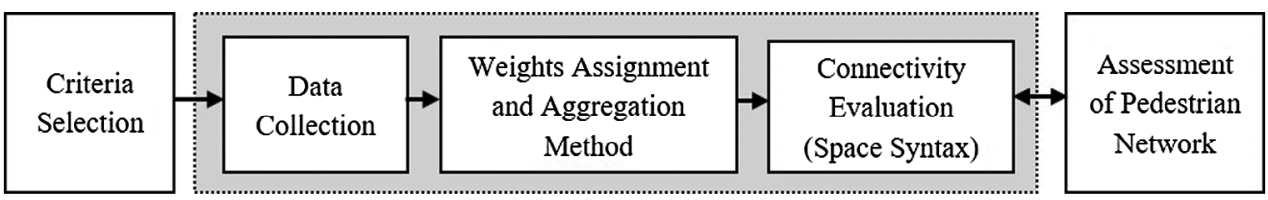

Figure 2. Steps followed to assess a pedestrian network.

because it evaluates different alternatives by using a number of qualitative and/or quantitative criteria with different weights (Ramos and Fonseca 2016). By using MCA, the streets can be ranked according to their walkable conditions, identifying the more and less walkable ones. This tool is often used in mobility studies (Longo et al. 2015), including in soft modes such as walking (Socharoentum and Karimi 2016). 


\section{Criteria selection}

The factors or criteria selected in this study were based on a literature review and the involvement of a group of experts. This group consisted of 41 experts in urban and transportation planning, such as civil engineers, geographers, urbanists and architects, namely PhD students, researchers and lecturers from the Universities of Porto (30) and Minho (11). The experts were found by contacting the urban planning departments at both universities. These research centres accepted the invitation to participate in the study. As promoting walking is a point on policy agendas, a growing number of urban planning experts have become interested in enhancing walkability (Kim, Park, and Lee 2014). Furthermore, involving experts is a common process in MCA with the aim of improving the analysis (Moura, Cambra, and Gonçalves 2017; Taleai and Amiri 2017). Weighting also requires a suitable way to make trade-offs between the criteria, having a direct influence on ordering the alternatives and, consequently, the results. In this approach, a quantitative weight method was used to define the relative importance of the criteria following the experts' vision.

Thus, the experts' participation was focused on two main issues considering the specific conditions found in the city of Oporto: (1) the criteria definition and (2) weighting and prioritizing the criteria. Their involvement followed a collaborative decision support system by filling in an online participation form - an expert survey. The purpose of the survey and range of questions were previously explained in individual working sessions. The survey that was carried out in 2015 was previously structured and based on a semi-closed question format and consisted of two main parts containing 12 questions. The first part was related to selecting the criteria and sub-criteria with more impact on walking. The survey included a list of sub-criteria and criteria to be selected by the experts according to their perception. Experts could also add new sub-criteria not included in the given list. Nonetheless, they largely confirmed the options given as only very few comments were added. For example, only three experts suggested including safety in the study, demonstrating that this factor is not critical in Oporto. In the second part, experts were invited to assign weights (prioritization) reflecting the importance the criteria selected have on walking. Based on this work, the following four criteria and respective nine sub-criteria were included in the study (Table 1).

Table 1. Weights assigned to the sub-criteria using pairwise comparison matrix.

\begin{tabular}{|c|c|c|c|c|}
\hline Criteria & Pairwise of sub-criteria & Experts' evaluations & Sub-criteria & Weights \\
\hline \multirow[t]{2}{*}{ Urban function } & Land use & $26.4 \%$ & Land use & 0.264 \\
\hline & Population density & $73.6 \%$ & Population density & 0.736 \\
\hline \multirow[t]{6}{*}{ Physical environment } & Visual dimension & $72.5 \%$ & Visual dimension & 0.498 \\
\hline & Human scale & $27.5 \%$ & & \\
\hline & Visual dimension & $60.4 \%$ & Slopes & 0.273 \\
\hline & Slopes & $39.6 \%$ & & \\
\hline & Human scale & $50.0 \%$ & Human scale & 0.229 \\
\hline & Slopes & $50.0 \%$ & & \\
\hline \multirow[t]{2}{*}{ Accessibility } & Public transportation & $57.6 \%$ & Public transportation & 0.576 \\
\hline & $\begin{array}{l}\text { Intelligent transporta- } \\
\text { tion systems }\end{array}$ & $42.4 \%$ & $\begin{array}{l}\text { Intelligent transportation } \\
\text { systems }\end{array}$ & 0.424 \\
\hline \multirow[t]{2}{*}{ Natural environment } & Green spaces & $56.5 \%$ & Green spaces & 0.565 \\
\hline & Microclimatic conditions & $43.5 \%$ & Microclimatic conditions & 0.435 \\
\hline
\end{tabular}


(1) The physical environment is one of the most analyzed topics in pedestrian studies, as mentioned in the literature review. In the study, it consists of three sub-criteria.

(a) Slopes: slopes are one of the most effective factors influencing walking, affecting travel speed, energy required, difficulty and potential of walking (Guo and Loo 2013). Many walkability indexes and studies were developed considering slopes in relation to other factors (Guo and Loo 2013; Kasemsuppakorn and Karimi 2013; Lundberg and Weber 2014). Furthermore, slopes have a direct influence on the physical environment and characteristics of the paths (Willis, Manaugh, and El-Geneidy 2013).

(b) Visual dimension: this attribute is related to various urban dimensions that influence pedestrians' satisfaction of walking, including building design, heritage preservation, visual richness, aesthetic dimensions, quality of spaces, among others. Visual dimension is considered as having a significant impact on the walking experience by various authors (Bahrainy and Khosravi 2013; Guo and Loo 2013; Wey and Chiu 2013; Lundberg and Weber 2014; Garcia and Lara 2015).

(c) Human scale: this is related to size, texture and articulation of physical elements that match the size and proportions of humans and correspond to the speed at which humans walk (Ewing and Handy 2009). Human scale is highly dependent on physical aspects, including street furniture, building details, distance to walk, etc. It is a relevant factor for walking (Bahrainy and Khosravi 2013; Phillips et al. 2013).

(2) Urban function is also a widely used criterion in pedestrian studies, especially concerning the impact caused by the population and land use in walking. For Leduc and Kann (2013), urban functions can be categorized as part of built-up areas (residential, industrial/business, transport areas) and non-built-up areas (agricultural and green areas, water bodies, etc.).

The sub-criteria considered were:

(a) Population density: this is one of the most used attribute because the population distribution and characteristics influence (and are influenced) by many factors: land use, location of services and activities, public transportation, traffic generation, etc. Population density was included in the studies carried out by Christiansen et al. (2014); Peiravian, Derrible, and ljaz (2014); Lerman and Omer (2016).

(b) Land use: this is an attribute also widely used in pedestrian studies (Manaugh and Geneidy 2011; Bahrainy and Khosravi 2013; Millward, Spinney, and Scott 2013; Kim, Park, and Lee 2014; Lamíquiz and Domínguez 2015; Lerman and Omer 2016) because it has a significant impact on the population distribution and their movements. As mentioned in the literature review, mixed land uses and commercial areas have a strong impact on pedestrian movements. The literature relating urban function with land-use conversion has been widely discussed (Zhou et al. 2016). Urban land is the spatial carrier of urban function and urban land use conversion brings about changes to urban functions. 
(3) Accessibility is also a widely used attribute in pedestrian studies and is considered the first level in the hierarchy of walking needs. Accessibility can be understood as the opportunity to access different activities/facilities in a given location, including components such as distance, characteristics of pavements, slopes, etc. In this study, accessibility considers the distance to public transportation facilities and the technological service provided by them as the other issues are included in other criteria, namely in the physical environment and urban function. The sub-criteria considered were:

(a) Public transportation: this attribute has been used by many authors to study and measure accessibility (Wey and Chiu 2013; Cubukcu et al. 2015; Garcia and Lara 2015). In fact, walking is the most used mode to access public transportation and is one of the travel modes used by people between an origin and a destination. In this study, walking distances to public transport were 400 metres to the bus stops and 800 metres to the light rail stations. These distances are recommended for this type of studies (Millward, Spinney, and Scott 2013; Kim, Park, and Lee 2014).

(b) Intelligent transportation: this is related to systems that provide real-time information for passengers at bus-stops, inside buses and the Internet on websites and mobile applications. It includes systems to improve the security provided to pedestrians namely by detection systems. This is innovative and not usually included in pedestrian studies.

(4) Various studies show that natural environment is a criterion that shapes walking (Lundberg and Weber 2014; Helbich et al. 2016). The two following sub-criteria were included in the analysis.

(a) Green spaces: urban greenery clearly benefits the climate and urban environment. Key benefits include improving the thermal comfort, air quality, reduction in urban noise and wind speed (Ng et al. 2012; Caprì et al. 2015; Panagopoulos, Duque, and Dan 2016). Green spaces also have a positive impact on the urban landscape, which also influences walking (Vojnovic et al. 2006).

(b) Microclimatic conditions: these are related to climate characteristics in the urban canopy layer between the building rooftops and ground surfaces, e.g., the pedestrian level ( $\mathrm{Ng}$ et al. 2012). Nevertheless, the quantitative relationship among the thermal comfort of pedestrians, microclimate variables and walking attitude at the scale of the street network is still an issue that needs more investigation (Caprì et al. 2015).

\section{Data collection and analysis, weights assignment and aggregation method}

After the criteria and sub-criteria were selected by the experts, the next step was to collect data concerning the conditions provided by the streets. Geographic data related to the streets, buildings, parks, etc. were collected, as well as statistical data concerning the population and buildings. All the streets were visited and analyzed, especially to collect the remaining missing data. 
The next step was to develop the MCA in order to prepare and evaluate all the sub-criteria and criteria by using the fuzzy method in GIS. As the data from the criteria was expressed in different quantitative and qualitative scales, the values had to be normalized so that they could be compared. The process was implemented through fuzzy logic with linear normalization, a common approach used in MCA and decision problems (Forés, Bovea, and Belis 2014). The fuzzy theory is based on a fuzzy membership grade (possibility) that ranges from 0.0 to 1.0 , indicating a continuous increase from non-membership to complete membership. The calculation was estimated by using the following sigmoidal function:

$$
f\left(x_{i}\right)=\left\{\begin{array}{l}
x=x_{\min }=0 \rightarrow f\left(x_{i}\right)=0 \\
x_{\min }<x_{i}<x_{\max } \rightarrow f\left(x_{i}\right)=\frac{x-x_{\min }}{x_{\max }-x_{\min }} \\
x=x_{\max } \rightarrow f\left(x_{i}\right)=1
\end{array}\right.
$$

$X_{i}$ - Element of the network $(i=1,2, \ldots, n)$

$X-X_{i}$ of elements of the network

Determining the importance of the criteria and sub-criteria for walking was the next step. The analytic hierarchy process was used to assign the weights given by the 41 experts (Table 1). Converting the experts' opinions into values was done by using a pairwise comparison matrix. As shown in Table 2, the sub-criteria and criteria weights were calculated by performing different pairs of combinations.

According to the final weights, the criteria mostly valued by the experts were the natural environment and accessibility. These results are in accordance with other pedestrian studies where natural environment (Caprì et al. 2015; Socharoentum and Karimi 2016) and accessibility (Cervero et al. 2009; Millward, Spinney, and Scott 2013; Garcia and Lara 2015; Gilderbloom, Riggs, and Meares 2015; Lamíquiz and Domínguez 2015) are seen as having a central role in decisions and the satisfaction of walking.

The final step of this stage was the aggregation that consists of incorporating the weights assigned by the experts to the sub-criteria and criteria. The method used was the Weighted Linear Combination (WLC), because it is an analytical approach that can be used when dealing with multi-attribute decision making (Silva 2015). In the WLC, the combination

Table 2. Weights assigned to the criteria using the pairwise comparison matrix.

\begin{tabular}{lccc}
\hline Criteria & Partial weights & \multicolumn{1}{c}{ Criteria } & Final weights \\
\hline Physical environment & $57.1 \%$ & Physical environment & 0.1794 \\
Urban function & $42.9 \%$ & Urban function & 0.1990 \\
Natural environment & $61.3 \%$ & & 0.3102 \\
Physical environment & $38.7 \%$ & Accessibility & \\
Physical environment & $35.7 \%$ & & 0.3114 \\
Accessibility & $64.3 \%$ & Natural environment & \\
Urban function & $44.4 \%$ & & \\
Accessibility & $55.6 \%$ & & 1.000 \\
Natural environment & $67.3 \%$ & & \\
Urban function & $32.7 \%$ & Sum & \\
Accessibility & $53.7 \%$ & & \\
Natural environment & $46.3 \%$ & & \\
\hline
\end{tabular}


resulted in applying the weights obtained by the pairwise combination to the conditions offered by the streets. Ranking prioritizing the walkable conditions provided by the streets is obtained by summing the results of each of the criteria. The higher the score, the more walkable the street is. WLC allows for a complete trade-off between the various criteria, meaning that a street with one very bad condition can be compensated by having other strong qualities. The WLC was performed on GIS and was calculated by using Equations (2) and (3).

$$
j=1,2, \ldots, 9 \quad S_{k}\left(x_{i}\right)=\sum_{i=0}^{n} f_{j}^{k}\left(x_{i}\right) w_{k j}
$$

$S_{k}\left(x_{i}\right)$ - Assessment of element $X_{i}$ for all the sub criteria $j$ of criteria $k$

$$
k=1,2, \ldots, 4 \quad T\left(x_{i}\right)=\sum_{i=0}^{n} S_{k}\left(x_{i}\right) w_{k}
$$

$T\left(x_{i}\right)$ - Assessment of all the criteria $k$ for element $X_{i}$ of the network

\section{Assessment of pedestrian network}

This paper argues that assessing a pedestrian network requires a street connectivity analysis. In fact, connectivity measures the degree to which dense and diverse urban activities are accessible. The principle is that in order for streets to be walkable, they must be connected. Even if a street provides good conditions for walking, it must be linked with other streets and spaces, otherwise people hardly go there on foot. In the study, connectivity was accessed with space syntax by using the DepthmapX software. Space syntax was adopted because it has various advantages compared to more simple street connectivity measures such as passive graphic notions, namely for calculating movements in network-configured human settlements and functional connectivity in networks (Tianxiang, Dong, and Shoubing 2015). The DepthmapX software performs a set of spatial network analyses designed to understand social processes within the physical environment (Jeong and Ban 2016). Based on the graph theory, the connectivity of a node can be defined as the number of other nodes directly connected to it. The analysis performed with space syntax shows a street connectivity ranging from 1 to 14 (Table 3). Higher space syntax values correspond to streets with many connections (nodes) and vice versa. These values were then normalized between 0.0 and 1.0 by fuzzy logic and inserted in the GIS database. A WLC was calculated again to obtain the final scores by using a weight of 0.5 for the criteria evaluation and 0.5 for street connectivity, as suggested by the experts. The result is an assessment of the pedestrian network,

Table 3. Normalization of the connectivity.

\begin{tabular}{lccc}
\hline Space Syntax & Normalization in GIS & Space Syntax & Normalization in GIS \\
\hline 1 & 0 & 8 & 0.5390 \\
2 & 0.0769 & 9 & 0.6159 \\
3 & 0.1540 & 10 & 0.6929 \\
4 & 0.2310 & 11 & 0.7700 \\
5 & 0.3080 & 12 & 0.8469 \\
6 & 0.3850 & 13 & 0.9240 \\
7 & 0.4620 & 14 & 1.0000 \\
\hline
\end{tabular}


showing the streets most suitable for walking, reflecting not only the conditions provided to pedestrians, but also their connectivity.

\section{Results}

The results considering the performance of the streets in the four criteria are presented in Figure 3. ${ }^{1}$ Green paths correspond to the streets with the highest scores while the red ones are those that rank the worst. In an individual analysis, natural environment is the criteria with the most favourable situation. It is the only criterion where $50 \%$ of streets scored greater than 0.50 , with more streets connected in some spatial continuities from the Douro River crossing the city centre to the peripheries of the delimited area. This is the result of the green spaces widespread around the city and the trees and shrubs planted on pavements. Physical environment obtained a slightly lower result, observing that $47 \%$ of the streets have a score above 0.50 . Particularly in the historic centre, near the river, there are many roads which score poorly due to slopes, derelict buildings and narrow streets. Urban function performs much more poorly, with only six streets ranked in the highest class. Globally, only $12 \%$ of
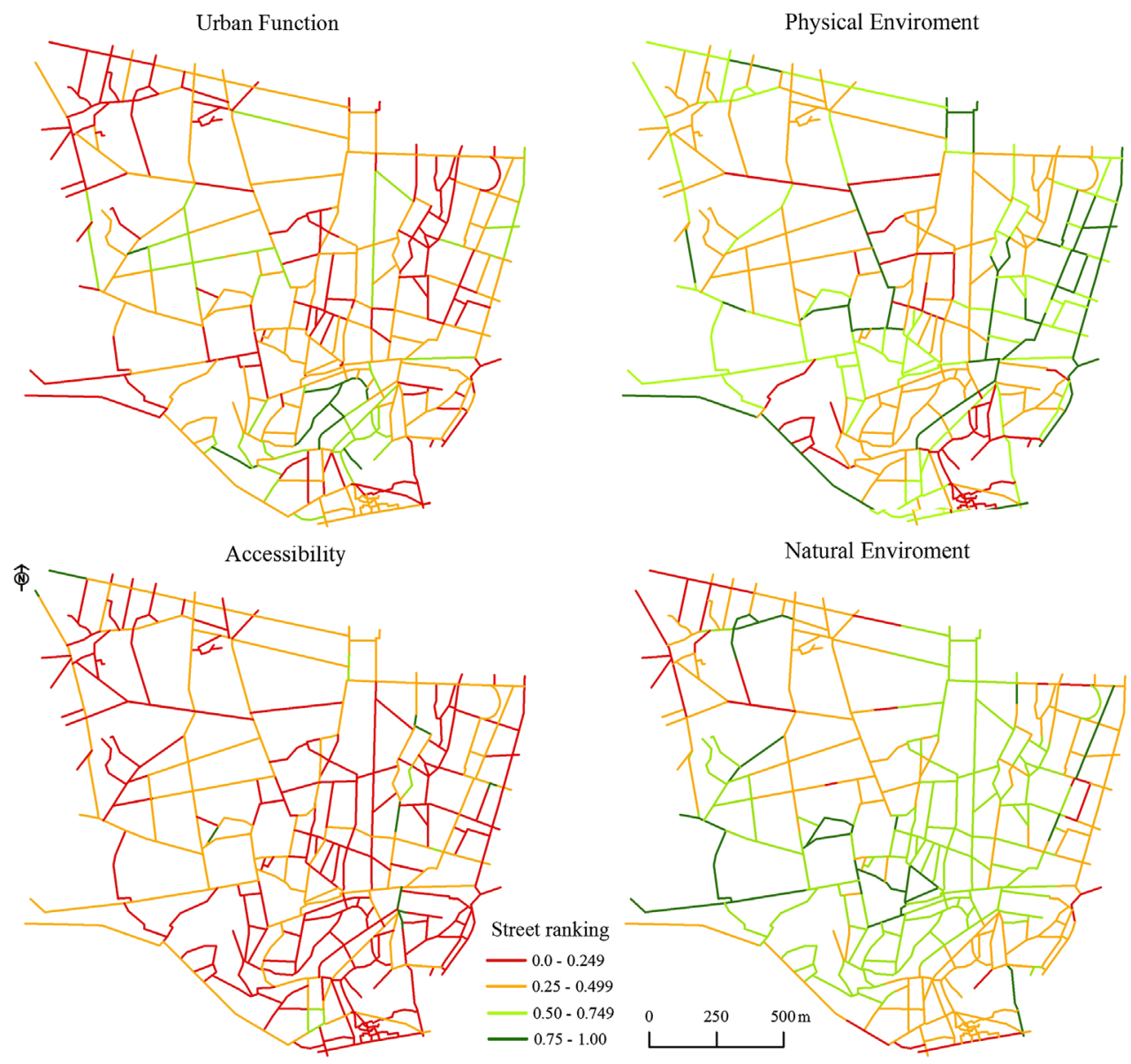

Figure 3. Walkability level of the streets considering the four criteria individually. 
the streets analyzed scored above 0.50 in this criterion, reflecting a reduced diversity of land use and population density, mainly in the historic centre. However, the criterion that performed worst was accessibility, with only $5 \%$ of the streets scoring above 0.50 . This is mostly due to the lack of intelligent information systems related to public transportation in the streets and the distribution (and distance) of bus stops around the city.

The ranking combining the four criteria was obtained from GIS analysis by overlaying the four layers and by applying the weights of Table 2. By analyzing the results presented in Figure 4, two main conclusions can be obtained. First, none of the streets analyzed obtained a final classification above 0.71 . The length of the streets best ranked is of 664 metres, corresponding to $1.4 \%$ of the total length of the streets analyzed. Considering that street ranking can range between 0 (very poor) and 1 (very good) and as only $18 \%$ of the street lengths analyzed scored above 0.5 , the conditions provided to pedestrians can be classified has being globally poor. In fact, this type of assessment scale is very common in multi-criteria research (Ramos and Fonseca 2016; Ward et al. 2016).

As described in the Data and methods section, besides the four criteria, street connectivity was also included in the study. The final map showing the connectivity level is presented in Figure 5. Results show the non-existence of a network of highly scored streets in this area. The streets that scored best are widespread around the urban space without connectivity and continuity. The streets best connected are located in the central area around Bolhão and Avenida dos Aliados. On the other hand, the streets with lower levels of connectivity are located in part of Ribeira and Boavista and mostly included secondary streets of local access.

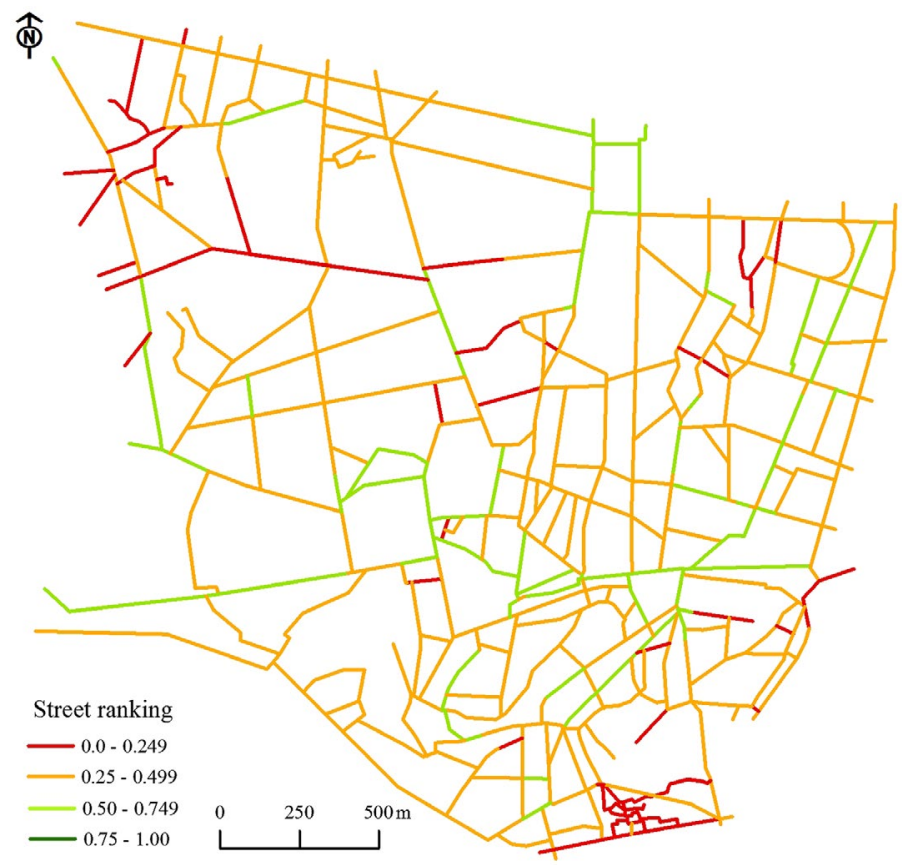

Figure 4. Street ranking considering the four criteria. 


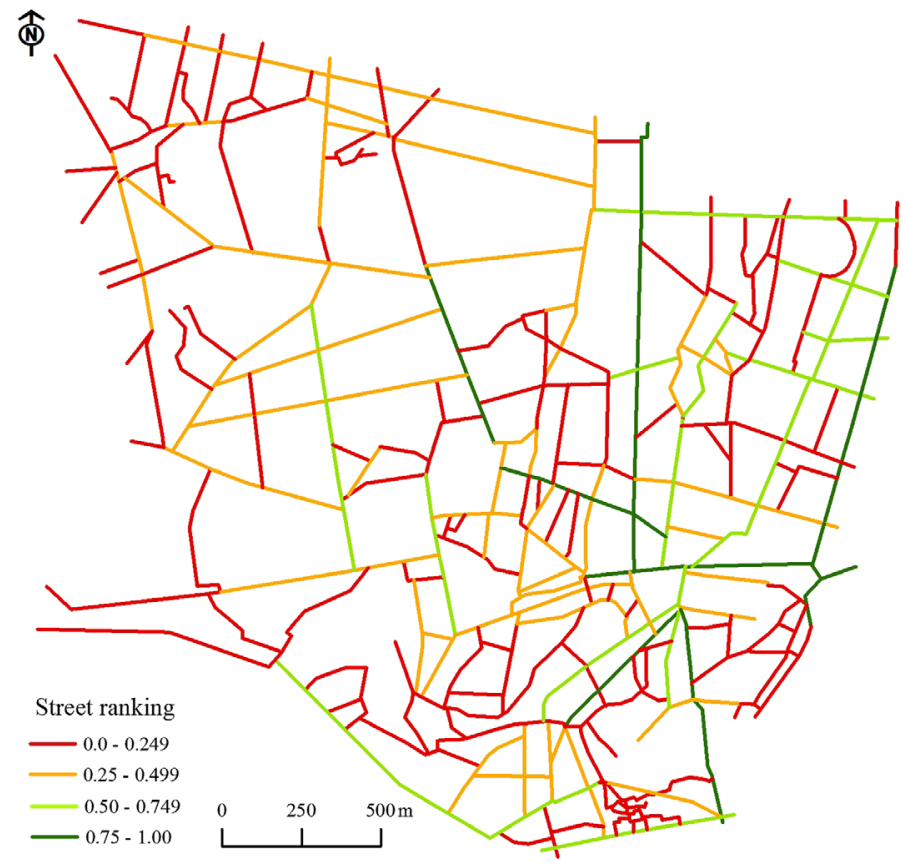

Figure 5. Street ranking considering street connectivity.

The final street ranking was achieved by combining the same weight $(0.5)$ with the criteria and the connectivity evaluations (Figure 6). In comparison to Figure 5, the inclusion of connectivity slightly improved walkability. Nonetheless, the conditions provided to pedestrians are globally low as only $20 \%$ of the total street length scored above 0.50 (Table 4). The highest score obtained ( 0.77 near S. Bento Station) is significantly lower than 1.0. The streets well ranked are mostly located in the city centre (Baixa), namely in Aliados, Bolhão and S. Bento Station. On the other hand, a significant number of streets were poorly ranked, having scores less than 0.25 . These streets are widespread around the whole area, mainly in Ribeira and Boavista. In many cases, they link highly scored streets, creating passing areas with fewer conditions for pedestrians. This also explains the lack of a network of pedestrian roads in the centre of Oporto providing similar and continuous conditions for pedestrians. As Figure 6 shows, there are only a few of the relatively well ranked streets that are continuously connected. There are streets with acceptable or good conditions, but others are short or interrupted by streets providing poor conditions. This can obviously discourage people from walking. On the other hand, these results can be very useful to improve the conditions provided by the streets and the pedestrian network, because less walkable streets and segments are identified. In some cases, the streets have unfavourable conditions for pedestrians that cannot be changed, such as the slope of some streets in Ribeira. Nevertheless, there are many streets where the conditions can be improved by implementing actions related to accessibility, urban rehabilitation, greening and urban landscaping. Providing pedestrian infrastructure and implementing policies to discipline traffic and car parking are important, not only to improve walkability but also to create a network of pedestrian streets. Thus, the approach and results obtained can be very helpful to guide urban and transportation planning actions to improve walkability. 


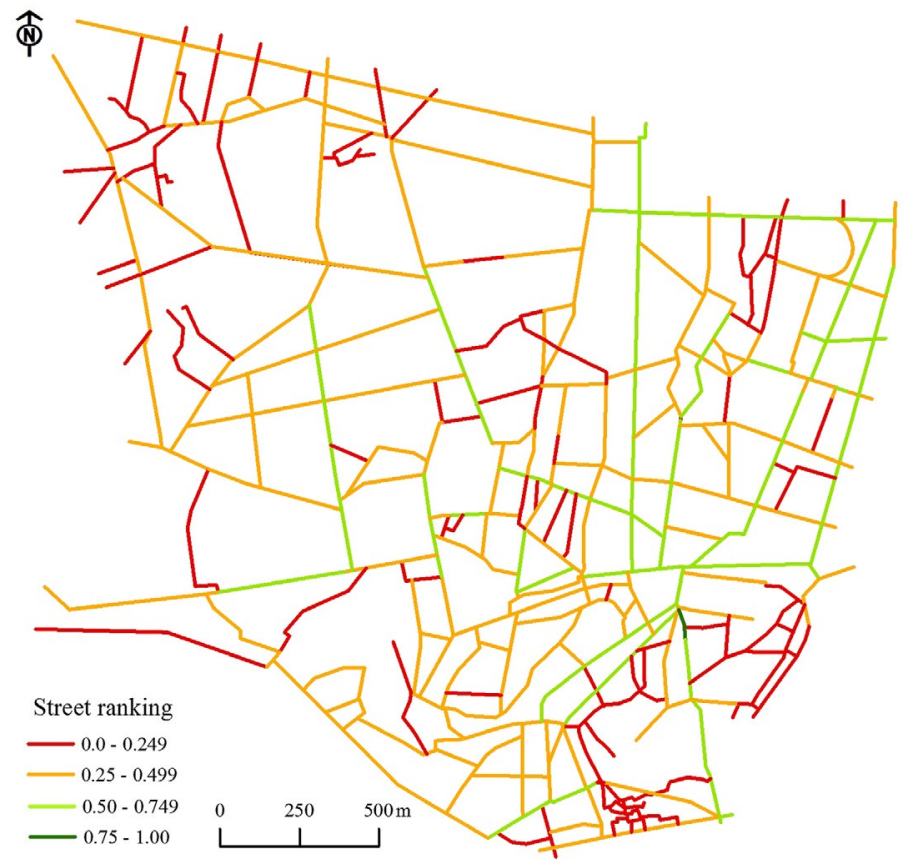

Figure 6. Final street ranking.

Table 4. Disaggregated results of final street ranking.

\begin{tabular}{lccc}
\hline Pedestrian classes & Number of street segments & Total length $(\mathrm{m})$ & Percentage (total length) \\
\hline $0.0-0.249$ & 120 & 12614.0 & 26.9 \\
$0.25-0.499$ & 217 & 25059.4 & 53.4 \\
$0.50-0.749$ & 82 & 9187.6 & 19.5 \\
$0.75-1.00$ & 1 & 72.0 & 0.2 \\
\hline
\end{tabular}

\section{Discussion and final remarks}

Identifying and assessing a pedestrian network is challenging mainly in large areas with multi-functionality and different urban and natural characteristics. The approach described in this paper was applied to the Oporto central area with the purpose of assessing a pedestrian network. The approach was supported in a GIS multi-criteria analysis where nine sub-criteria and four criteria were selected and weighted according to a panel of 41 experts. Street connectivity was also included in the approach by using space syntax. To obtain the final ranking, all the values were normalized and overlaid.

The approach was very useful in identifying how walkable the streets are and to understand their linkages and spatial arrangement. These rankings can be used to identify existing problems and propose solutions. Results clearly show that a significant number of streets are not very attractive for pedestrians in the Oporto central area. In fact, the area analyzed does not have a pedestrian network with high walkable levels. On the contrary, various paths present changeable conditions, with discontinuous and irregular streets which can encourage car usage. Results also show a lack of a pedestrian network in this area. The streets exhibited scores significantly lower than 1 (the maximum score achieved was 0.77 in only 
one street segment) while the others scored globally above 0.50 . There is some connectivity between streets which scored reasonably (0.50-0.749) around the S. Bento Station and Avenida dos Aliados, but in the remaining area, the connections and conditions provided for pedestrians are poor. On the other hand, the results clearly identified the streets with more problems. This assessment is helpful in supporting urban planning decisions aiming at improving walkability and the network connectivity. Some of the problems identified arise from adopting planning policies that gave pedestrians little consideration in the past. As Li, Gao, and Yin (2013) highlight, the pedestrian mode was often the last aspect to be considered in urban planning. During recent decades, cities have mostly been planned for cars and not for pedestrians. However, as nowadays walking and cycling are becoming more important, cities must also be planned with accessibility as a key criterion of the planning and design process (Vojnovic et al. 2006).

During recent years, the Oporto entities have implemented various urban planning policies for it to become a smart sustainable city, including making mobility more sustainable. For example, some streets, such as Rua das Flores, were recently converted into exclusive pedestrian zones. The city has also adopted many other urban policies having a direct impact on walkability. The physical and functional rehabilitation of the historic centre is perhaps the most visible policy. Rehabilitation makes cities more pleasant to walk in, having a direct impact on the built visual dimension, human scale, land use, population density and public transportation services. Built rehabilitation is important as many researchers found that people were much more likely to walk to work if it was feasible, safe, comfortable and visually appealing (Vojnovic et al. 2006). In functional terms, the city centre has been invigorated as a consequence of the increase in tourism during the last few years. Several studies also show that commercial activities are related to greater pedestrian movement (Bahrainy and Khosravi 2013; Lamíquiz and Domínguez 2015; Lerman and Omer 2016). The green areas found in the central area of the city and along some streets (Avenida dos Aliados, Palácio de Cristal, Restauração, Praça dos Mártires da Pátria, etc.) are also positive. In fact, green spaces are linked to higher walkable scores, creating more attractive walking environments and having a positive impact on the microclimatic conditions found at the pedestrian level (Lwin and Murayama 2011; Adkins et al. 2012; Caprì et al. 2015).

Nonetheless, the multi-functionality and different densities found in the centre of Oporto are critical points. Although some streets are exclusively pedestrian and have a strong commercial function (Santa Catarina, Cedofeita and Flores, for example), the population density is relatively reduced in these areas. This problem shows an unbalanced land use. It is a space for commerce and services, but where the population density is relatively low, meaning that probably part of the pedestrians do not live there. Building rehabilitation can be essential to attract more inhabitants to these areas. Enhancing coverage using public transport, especially bus stops with suitable intelligent transportation systems, is also important to reduce car dependency and make urban mobility more sustainable. As some studies show, utilitarian pedestrians are the most frequent users of public transportation services (Kim, Park, and Lee 2014; Garcia and Lara 2015). If the distance to walk is too long and no information is provided, people will be encouraged to use private vehicles.

Finally, there are some aspects that could be improved in future developments. It will be particularly important to support the weighting process in a larger and representative sample. In fact, in identical approaches, some authors such as Taleai and Amiri (2017) adopted a combined system involving not only a group of experts, but also non-experts, such as 
residents to strengthen the approach. Including other criteria/sub-criteria could also be relevant because there are still some components such as safety that were not included in the analysis. Some authors, such as Agrawal, Schlossberg, and Irvin (2008), show that besides minimizing time and distance, safety is a secondary factor influencing route choice, as well as the attractiveness of the route and the quality of the pavements. In addition, in Oporto safety was not perceived by the experts as being critical, but the inclusion of this criterion could be important in other cities. By using specific criteria included in the database, the approach has the potential to be upgraded and included in smart navigation systems and applications for pedestrians. Similar systems were developed with the aim of encouraging walkability when pedestrians encounter unfamiliar environments (Fang, Qingquan, and Shaw 2015). Traditionally, pedestrian navigation is based on the guidance of pedestrians walking between identifiable origins and destinations. By using the MCA, this application can be used by pedestrians to identify paths between a specific origin and destination with different characteristics: flat paths, green paths, paths crossing heritage areas, commercial zones, etc. As urban areas are becoming more complex, the system could provide an integrated response in real time meeting the physical and psychological needs of pedestrians. Moreover, in order to confirm the results, the described approach needs to be properly validated. The literature on walking models shows that, depending on the researchers' objectives, various methods have been used to test the reliability of such procedures. For Moura, Cambra, and Gonçalves (2017), the lack of an organized set of validation methods for walkability assessment tools is a challenge when the assessment results are interpreted and applied in urban and transport planning. Nonetheless, three main methods have mostly been used: (1) pedestrian counts relating walkability scores to pedestrian flows. For example, this method was used by Yin et al. (2015) and by Yin (2017); (2) street surveys, linking walkability scores to people's perception of the conditions provided. For example, this method was used by Kelly et al. (2011) and by Sung et al. (2015); and (3) home-based surveys, relating walkability scores to people's travel routines and lifestyle to understand the pedestrian personal characteristics. For example, this method was used by Millward, Spinney, and Scott (2013) and by Moura, Cambra, and Gonçalves (2017). One of these methods could be used in the future to test the described approach. The first option consists of counting the pedestrians to confirm whether the better ranked streets have more people walking. Alternatively, pedestrians can be asked about their perception of walking on the streets of Oporto, identifying the most and least walkable streets. The intention is to present the results of this validity testing in a future study.

Considering its replicability and potential in terms of urban planning and technological application, the approach described in this paper has high potential to improve walkability in cities and to design pedestrian networks towards a more sustainable pattern of urban development.

\section{Note}

1. The figures can be viewed in colour in the online version of the journal at https://doi.org/10. 1080/13574809.2017.1343087

\section{Disclosure statement}

No potential conflict of interest was reported by the authors. 


\section{Funding}

This research was funded by the CIVITAS CAPITAL (Ref. No. MOVE/FP7/604778/CAPITAL) and by the Centre for Territory, Environment and Construction of the School of Engineering of University of Minho.

\section{ORCID}

Mona Jabbari (iD) http://orcid.org/0000-0002-5447-8128

Fernando Fonseca (D) http://orcid.org/0000-0003-2336-175X

Rui Ramos (D) http://orcid.org/0000-0002-6690-5940

\section{References}

Adkins, A., J. Dill, G. Luhr, and M. Neal. 2012. “Unpacking Walkability: Testing the Influence of Urban Design Features on Perceptions of Walking Environment Attractiveness." Journal of Urban Design 17 (4): 499-510.

Agrawal, A., M. Schlossberg, and K. Irvin. 2008. "How Far, by Which Route and Why? A Spatial Analysis of Pedestrian Preference." Journal of Urban Design 13 (1): 81-98.

Azmi, D., and P. Ahmad. 2015. "A GIS Approach: Determinant of Neighbourhood Environment Indices in Influencing Walkability between Two Precincts in Putrajaya." Procedia Social and Behavioral Sciences 170: 557-566.

Babiano, I. 2016. "Pedestrian's Needs Matter: Examining Manila's Walking Environment." Transport Policy 45: 107-115.

Bahrainy, H., and H. Khosravi. 2013. "The Impact of Urban Design Features and Qualities on Walkability and Health in under-Construction Environments: The Case of Hashtgerd New Town in Iran." Cities 31: 17-28.

Blečić, I., A. Cecchini, T. Congiu, G. Fancello, and G. Trunfio. 2015. “Evaluating Walkability: A CapabilityWise Planning and Design Supportsystem." International Journal of Geographical Information Science 29 (8): 1350-1374.

Caprì, S., M. Ignaccolo, G. Inturri, and M. Pira. 2015. "Green Walking Networks for Climate Change Adaptation." Transportation Research Part D 45: 84-95.

Cervero, R., O. Sarmiento, E. Jacoby, L. Gomez, and A. Meiman. 2009. "Influences of Built Environments on Walking and Cycling: Lessons from Bogota." International Journal of Sustainable Transportation 3 (4): 203-226.

Christiansen, L., M. Toftager, J. Schipperijn, A. Ersbøll, and B. Corti. 2014. "School Site Walkability and Active School Transport-Association, Mediation and Moderation." Journal of Transport Geography 34: 7-15.

Cubukcu, E., B. Hepguzel, Z. Onder, and B. Tumer. 2015. "Active Living for Sustainable Future: A Model to Measure "Walk Scores" via Geographic Information Systems." Procedia Social and Behavioral Sciences 168: 229-237.

EC (European Commission). 2011. White Paper: Roadmap to Single European Transport Area, towards a Competitive and Resource-Efficient Transport System. Report 144. Brussels: European Commission.

Ewing, R., and S. Handy. 2009. "Measuring the Unmeasurable: Urban Design Qualities Related to Walkability." Journal of Urban Design 14 (1): 65-84.

Fang, Z., L. Qingquan, and S. Shaw. 2015. "What about People in Pedestrian Navigation?" Geo-Spatial Information Science 18 (4): 135-150.

Ferrer, S., T. Ruiz, and L. Mars. 2015. "A Qualitative Study on the Role of the Built Environment for Short Walking Trips." Transportation Research Part F: Traffic Psychology and Behaviour 33: 141-160.

Forés, V., M. Bovea, and V. Belis. 2014. "A Holistic Review of Applied Methodologies for Assessing and Selecting the Optimal Technological Alternative from a Sustainability Perspective." Journal of Cleaner Production 70: 259-281.

Forsyth, A., and M. Southworth. 2008. "Cities Afoot?Pedestrians, Walkability and Urban Design." Journal of Urban Design 13 (1): 1-3. 
Garcia, R., and J. Lara. 2015. "Q-PLOS, Developing an Alternative Walking Index. A Method Based on Urban Design Quality." Cities 45: 7-17.

Geurs, K., and B. van Wee. 2004. "Accessibility Evaluation of Land-Use and Transport Strategies: Review and Research Directions." Journal of Transport Geography 12: 127-140.

Gilderbloom, J., W. Riggs, and W. Meares. 2015.“'Does Walkability Matter? An Examination of Walkability's Impact on Housing Values, Foreclosures and Crime." Cities 42: 13-24.

Guo, Z., and B. Loo. 2013. "Pedestrian Environment and Route Choice: Evidence from New York City and Hong Kong." Journal of Transport Geography 28: 124-136.

Helbich, M., M. Emmichoven, M. Dijst, M. Kwan, F. Pierik, and S. Vries. 2016. "Natural and Built Environmental Exposures on Children's Active School Travel: A Dutch Global Positioning SystemBased Cross-Sectional Study." Health \& Place 39: 101-109.

Jeong, S., and Y. Ban. 2016. "A Point-Based Angular Analysis Model for Identifying Attributes of Spaces at Nodes in Street Networks." Physica A 450: 71-84.

Kasemsuppakorn, P., and H. Karimi. 2013. "A Pedestrian Network Construction Algorithm Based on Multiple GPS Traces." Transportation Research Part C 26: 285-300.

Kelly, C., M. Tight, F. Hodgson, and M. Page. 2011. "A Comparison of Three Methods for Assessing the Walkability of the Pedestrian Environment." Journal of Transport Geography 19: 1500-1508.

Kim, S., S. Park, and S. Lee. 2014. “Meso- or Micro-Scale? Environmental Factors Influencing Pedestrian Satisfaction." Transportation Research Part D 30: 10-20.

Koh, P., and Y. Wong. 2013. "Comparing Pedestrians' Needs and Behaviours in Different Land Use Environments." Journal of Transport Geography 26: 43-50.

Lamíquiz, P., and J. Domínguez. 2015. "Effects of Built Environment on Walking at the Neighbourhood Scale. A New Role for Street Networks by Modelling Their Configurational Accessibility?" Transportation Research Part A 74: 148-163.

Leduc, W., and F. Kann. 2013. “Spatial Planning Based on Urban Energy Harvesting toward Productive Urban Regions." Journal of Cleaner Production 39: 180-190.

Lee, S., and E. Talen. 2014. "Measuring Walkability: A Note on Auditing Methods." Journal of Urban Design 19 (3): 368-388.

Lerman, Y., and I. Omer. 2016. “Urban Area Types and Spatial Distribution of Pedestrians: Lessons from Tel Aviv." Computers, Environment and Urban Systems 55: 11-23.

Li, J., Y. Gao, and H. Yin. 2013. "Pedestrian Facilities Planning on Tianjin New Area Program." Procedia Social and Behavioral Sciences 96: 683-692.

Longo, A., W. Hutchinson, R. Hunter, M. Tully, and F. Kee. 2015. “Demand Response to Improved Walking Infrastructure: A Study into the Economics of Walking and Health Behaviour Change." Social Science \& Medicine 143: 107-116.

Lundberg, B., and J. Weber. 2014. “Non-Motorized Transport and University Populations: An Analysis of Connectivity and Network Perceptions." Journal of Transport Geography 39: 165-178.

Lwin, K., and Y. Murayama. 2011. "Modelling of Urban Green Space Walkability: Ecofriendly Walk Score Calculator." Computers, Environment and Urban Systems 35 (5): 408-420.

Maleki, M., M. Zain, and A. Ismail. 2012."Variables Communalities and Dependence to Factors of Street System, Density, and Mixed Land Use in Sustainable Site Design." Sustainable Cities and Society 3: 46-53.

Manaugh, K., and A. Geneidy. 2011. "Validating Walkability Indices: How Do Different Households Respond to the Walkability of Their Neighborhood?" Transportation Research Part D 16: 309-315.

Millward, H., J. Spinney, and D. Scott. 2013. “Active-Transport Walking Behavior: Destinations, Durations, Distances." Journal of Transport Geography 28: 101-110.

Moura, F., P. Cambra, and A. Gonçalves. 2017. “Measuring Walkability for Distinct Pedestrian Groups with a Participatory Assessment Method: A Case Study in Lisbon." Landscape and Urban Planning 157: 282-296.

Nasir, M., C. Lim, S. Nahavandi, and D. Creighton. 2014. "A Genetic Fuzzy System to Model Pedestrian Walking Path in a Built Environment." Simulation Modelling Practice and Theory 45: 18-34.

Ng, E., L. Chen, Y.Wang, and C. Yuan. 2012. "A Study on the Cooling Effects of Greening in a High-Density City: An Experience from Hong Kong." Building and Environment 47: 256-271. 
Panagopoulos, T., J. Duque, and M. Dan. 2016."Urban Planning with Respect to Environmental Quality and Human Well-Being." Environmental Pollution 208: 137-144.

Peiravian, F., S. Derrible, and F. ljaz. 2014. "Development and Application of the Pedestrian Environment Index (PEI)." Journal of Transport Geography 39: 73-84.

Phillips, J., N. Walford, A. Hockey, N. Foreman, and M. Lewis. 2013. "Older People and Outdoor Environments: Pedestrian Anxieties and Barriers in the Use of Familiar and Unfamiliar Spaces Distance to the Destination." Geoforum 47: 113-124.

Ramos, R., and F. Fonseca. 2016. "A Methodology to Identify a Network of Industrial Parks in the Ave Valley, Portugal." European Planning Studies 24: 1844-1862.

Silva, L. 2015. “Environmental Quality Health Index for Cities.” Habitat International 45: 29-35.

Socharoentum, M., and A. Karimi. 2016."Multi-Modal Transportation with Multi-Criteria Walking (MMTMCW): Personalized Route Recommender." Computers, Environment and Urban Systems 55: 44-54.

SP (Statistics Portugal). 2012. 15th Housing and Population Census. Lisbon: INE.

Sung, H., H. Go, C. Choi, S. Cheon, and S. Park. 2015. "Effects of Street-Level Physical Environment and Zoning on Walking Activity in Seoul, Korea." Land Use Policy 49: 152-160.

Taleai, M., and E. Amiri. 2017. "Spatial Multi-Criteria and Multi-Scale Evaluation of Walkability Potential at Street Segment Level: A Case Study of Tehran." Sustainable Cities and Society, 31, 37-50. doi:10.1016/j. scs.2017.02.011.

Tianxiang, Y., J. Dong, and W. Shoubing. 2015. “Applying and Exploring a New Modeling Approach of Functional Connectivity regarding Ecological Network: A Case Study on the Dynamic Lines of Space Syntax." Ecological Modelling 318: 126-137.

Velaga, N., M. Beecroft, J. Nelson, D. Corsar, and P. Edwards. 2012."Transport Poverty Meets the Digital Divide: Accessibility and Connectivity in Rural Communities." Journal of Transport Geography 21: 102-112.

Vojnovic, I., C. Elmoore, J. Holtrop, and S. Bruch. 2006. "The Renewed Interest in Urban Form and Public Health: Promoting Increased Physical Activity in Michigan." Cities 23 (1): 1-17.

Walford, N., E. Samarasundera, J. Phillips, A. Hockey, and N. Foreman. 2011. “Older People's Navigation of Urban Areas as Pedestrians: Measuring Quality of the Built Environment Using Oral Narratives and Virtual Routes." Landscape and Urban Planning 100: 163-168.

Ward, E., H. Dimitriou, P.Wright, and M. Dean. 2016. "Application of Policy-Led Multi-Criteria Analysis to the Project Appraisal of the Northern Line Extension, London." Research in Transportation Economics 58: 46-80.

Wey, W., and Y. Chiu. 2013. "Assessing the Walkability of Pedestrian Environment under the TransitOriented Development." Habitat International 38: 106-118.

Willis, D., K. Manaugh, and A. El-Geneidy. 2013. "Uniquely Satisfied: Exploring Cyclist Satisfaction." Transportation Research Part F 18: 136-147.

Yin, L. 2017. "Street Level Urban Design Qualities for Walkability: Combining 2D and 3D GIS Measures." Computers, Environment and Urban Systems 64: 288-296.

Yin, L., Q. Cheng, Z. Wang, and Z. Shao. 2015. "'Big Data' for Pedestrian Volume: Exploring the Use of Google Street View Images for Pedestrian Counts." Applied Geography 63: 337-345.

Zhou, G., C. Li, M. Li, J. Zhang, and Y. Liu. 2016. "Agglomeration and Diffusion of Urban Functions: An Approach Based on Urban Land Use Conversion." Habitat International 56: 20-30. 